\title{
Strategy use of Russian pre-service TEFL university students: using a strategy inventory for program effectiveness evaluation
}

\author{
Alla ZaReVA \\ ANNA FOMINA* \\ Old Dominion University, USA
}

Received: 9 March 2012 Accepted: 24 December 2012

\begin{abstract}
The focus of the present study is on identifying categories of learning strategies that are mostly used by Russian university students in an English Linguistics Program with a TEFL concentration. The more specific goal of the study is to offer a model of evaluation of the effectiveness of TEFL-oriented programs in terms of the language learning strategies their students use and recognize as pedagogically applicable to their EFL environment. To this end, two groups of students were compared on their self-reported frequency of strategy use $-1^{\text {st }}$ year students $(n=23)$, who had just entered the program, and $4^{\text {th }}$ year students $(n=38)$, who were close to graduating from the program and entering the teaching profession. The main instrument used in the study was a version of the Strategy Inventory for Language Learning (SILL), designed by Oxford (1990). Overall, both groups showed high to medium frequency of use of all strategy categories; however, the $4^{\text {th }}$ year students revealed a more finelygrained scale of strategy use priorities. The findings of the study can help curriculum designers and instructors refine the focus of their TEFL-track programs and make informed decisions about emphases and de-emphases in their students' training.
\end{abstract}

KEYWORDS: language learning strategies, ESL/EFL strategy use, pre-service teachers, TEFL program, SILL

\section{RESUMEN}

El presente estudio se propone identificar las categorías de estrategias de aprendizaje más utilizadas por estudiantes universitarios rusos en un programa de lingüística en inglés con una concentración TEFL. El fin principal es ofrecer un modelo que sirva para evaluar la efectividad de programas TEFL en términos de estrategias de aprendizaje de idiomas usadas por los estudiantes y aplicables a su entorno EFL. A tal fin, se compararon dos grupos de estudiantes partiendo de una encuesta sobre la frecuencia del uso de estrategias alumnos del 1er año ( $\mathrm{n}=23)$, que acababan de iniciar el programa, y alumnos de $4^{\circ}$ año ( $\mathrm{n}=38$ ), a punto de graduarse y ejercer la profesión de docente. El instrumento utilizado en el estudio fue una versión del Inventario de Estrategias de Aprendizaje de idiomas (SILL, del inglés Strategy Inventory for Language Learning), diseñando por Oxford (1990). Globalmente, ambos grupos demostraron una frecuencia de alta a media en el uso de todas las categorías de estrategias. Sin embargo, los alumnos de $4^{\circ}$ año mostraron una escala más precisa en el uso de estrategias. Los resultados del estudio pueden ayudar a docentes y diseñadores de currículos a perfeccionar el enfoque de sus programas en la modalidad TEFL y tomar decisiones fundamentadas en cuanto a lo que se debe enfatizar o no durante la formación de sus alumnos.

PALABRAS CLAVE: estrategias de aprendizaje, uso de estrategias en ESL/EFL, profesores en formación, programas TEFL, SILL

\footnotetext{
* Address for correspondence: Alla Zareva. Department of English. 5000 Batten Arts and Letters. Old Dominion University. Norfolk, VA 23529 USA. E-mail: azareva@odu.edu
} 


\section{INTRODUCTION}

Language learning strategies have received much attention since the mid 1970s as the development of learners' strategic competence has started to be seen as part of the development of their communicative competence (Celce- Mercia, 2001; Oxford, 1990, 2001). It has also become widely accepted that language learning requires learners' active involvement in the process of language acquisition, hence, their strategy use reveals much about the way they select, acquire, organize, relate knowledge, or exercise control over the tasks they are involved in (Oxford, 1990). This active involvement on learners' part also suggests that the burden of responsibility of developing strategic competence (i.e. the knowledge of a range of language learning strategies) is shared between learners and teachers in that learners are ultimately responsible for choosing and implementing appropriate strategies (Cohen, 1998) and instructors become ultimately responsible for incorporating strategy instruction (both implicit and explicit) in their language teaching practices to provide their students with the strategy "tools" to become independent learners.

University students, who are planning to teach English as a foreign language (EFL), are in a special position in this regard since they are positioned simultaneously as both learners and would-be teachers in the course of their education-i.e. they are still doing coursework aimed at increasing their mastery of English while, at the same time, they are also taking courses that inform them pedagogically about teaching English as a foreign language (TEFL). Interestingly, the research on the strategy use of pre-service TEFL students is scarce and one possible explanation of this state of affairs is that these students are already considered to be "successful learners" by virtue of being enrolled in TEFL-training university programs and as such they are not very "interesting” research subjects in that they do not reveal any typical language learning problems that may need immediate attention. We take a different tack on this issue. We would argue that there is a need for more research into the language learning strategies of pre-service students in TEFL-track programs in the local socio-cultural context of their education to uncover the specificities of a "successful learner" in that context. Such a focus will allow us to look at strategic competence as a global as well as local phenomenon. On the other hand, there is also a need for studies that explore what strategies are used and, potentially, perceived as desirable by pre-service TEFL students from a learner point of view because the same strategies will most probably be promoted by these same students when they start teaching. Finally, such an approach could be helpful to TEFL Program curriculum designers and instructors in that it will provide them with a tool for program evaluation of the effectiveness of the strategic competence training they offer to their students. This, in turn, can potentially inform some of Program's pedagogical decisions about certain emphases (and/or de-emphases) they may need to implement in their students' coursework. 
The focus of the present study is on identifying the categories of learning strategies that are mostly used by Russian university students enrolled in an English Linguistics Program with a TEFL concentration. The more specific goal of the study is to offer a model of evaluation of the effectiveness of TEFL-oriented university programs in terms of the language learning strategies their students use and recognize as pedagogically useful in an EFL environment. We will do so by comparing proficient beginning students, who have just entered the program, with final-year students, who are close to exiting the program and entering the teaching profession. Such kind of evaluation is of value from several perspectives: First, it establishes the breadth of strategies that beginning students bring to a TEFL program as they enter their specialized language education. In turn, it will help program curriculum designers refine the focus of both the linguistic and pedagogical coursework the students do during their studies by allowing them to identify the strategies the students already have in place at the beginning of their studies and the ones that will need specific instruction and emphasis throughout different subject areas. Secondly, it will help instructors address possible difficulties in implementing new learning strategies and evaluate their effectiveness with regard to the specificities of some local educational and cultural norms (in this case-Russia). Finally, it will allow for evaluation of a program's effectiveness in developing TEFL specialists that are equipped, both personally and professionally, with language learning strategies that are pedagogically sound and valued.

The rest of the paper is organized as follows: First, we will briefly discuss the role of strategies in L2 learning and the multitude of factors that affect it. The overview will aim at highlighting the complexity of the phenomenon, the impact of some of the most prominent factors that influence it, and the findings regarding the value of strategy use. This will be followed by a brief description of SILL, as one of the most frequently used instruments in strategy research, with a focus on its validity and reliability as an instrument. Next, we will present the details of an experiment we conducted with two groups of pre-service students enrolled in a TEFL-track Program at a Russian university. Finally, we will conclude with a discussion of the findings with respect to some general trends in strategy use among the two groups of participants, the specificities of the educational and cultural norms in Russia, and the usefulness of SILL for the purposes of program effectiveness evaluation.

\section{OVERVIEW OF LANGUAGE LEARNING STRATEGY USE}

A great deal of the strategy research has been devoted to finding out the strategies that good language learners use to enhance their own learning, which made it possible to identify an impressive array of "successful" language learning strategies that can be taught to learners at all levels of proficiency (Hsiao, 2004; Oxford, 2003). The question what strategies learners 
may decide to use (or not to use) in a given situation is not a straightforward one as the choice of strategies can be influenced by a number of factors, some of which are internal to learners and others-external. On the one hand, strategy use is to a large extent an individual decision that depends on an individual learner's cognitive predisposition or personality traits, the development of his/her metacognition and level of proficiency, as well as whether a learner's goal is to acquire social, academic, and/or vocationally-specific language (Anderson, 2005; Oxford, 2003). On the other hand, individuals function in a variety of social contexts which play a crucial role in shaping their cognitive and social development. Thus, learning cannot be fully understood without considering the situated contexts in which strategies emerge and develop. Along the same lines, the external factors that should be considered in discussions of strategy selection and use should also include the socio-cultural values of the learning situation and whether the learning context is a second language (L2) or foreign language setting (Chamot, 2004; Cohen, 2003; Oxford, Cho, Leung, \& Kim, 2004). Finally, we cannot have good understanding of learners' strategy use without considering the nature of the tasks they are involved in since the complexity and the demands of the task will trigger different strategies.

Inherently, no strategy is good or bad in itself but it becomes useful if, at least, three conditions are present: (1) the strategy is relevant to the L2 task at hand, (2) a learner links it with other relevant strategies for the task, and (3) the strategy matches the learner's general learning style preferences to some extent (Oxford, 2003). These conditions bring to the fore two additional dependencies related to strategy use-i.e. first, strategy selection is tightly linked to learners' learning styles and, second, strategy selection is not an isolated behavior; rather, it is "a process of orchestrating more than one action to accomplish an L2 task" (Anderson, 2005: 757). In other words, L2 learners should be able to draw upon a variety of strategies from a wide strategy repertoire to accomplish their task of learning and mastering another language.

Given the interest in strategy selection for language learning purposes, the complexity of the phenomenon and the multitude of factors that influence it, it is not surprising that different researchers have used different instruments in their studies across a variety of learners (with respect to age, gender, proficiency level, educational level, etc.) and learning situations. This wealth of research and findings has given us better understanding of the general picture of strategy use, deeper insights into the specific influences of many internal and external variables, as well as more confidence in the validity and reliability of the strategy instruments developed by different researchers (for an overview, see Chamot 2004, 2005: Cohen, 1998; Hsiao \& Oxford, 2002).

One of the most widely used instruments which, over the decades of strategy research, has been found to have high reliability and validity across a variety of research designs is the Strategy Inventory of Language Learning (SILL) for ESL and EFL learners developed by 
Oxford (1990). The shorter version of the instrument consists of 50 items, drawn from systematic lists of language learning strategies, which create a taxonomy of strategies that can be grouped into six groups (also called sub-scales or factors):

a) metacognitive strategies - the strategies used for organizing, planning, focusing and evaluating one's own learning (e.g., linking new with old information, seeking practice opportunities, self-monitoring, etc.);

b) cognitive strategies — strategies used for analyzing, classifying, and linking new information with existing schemata (e.g., repeating, getting the idea quickly, analyzing structures, note-taking, etc.);

c) social strategies - the ones used for facilitating the interaction by asking questions, and cooperating with others in the learning process, (e.g., asking for clarification, cooperating with others, developing cultural understanding, etc.);

d) compensatory strategies - those include strategies that learners need to overcome limitations in their language production or perception (e.g., switching to their native language, guessing, using circumlocution, etc.);

e) memory-related strategies - the strategies used for storing and retrieving new information from memory when needed for communication (e.g., grouping, representing sounds in memory, structured reviewing, using physical response, etc.).

f) affective strategies-strategies used for handling feelings, attitudes, and motivations (e.g., lowering anxiety by use of music, encouraging oneself, discussing one's feelings about language learning with others, etc.).

By and large, these six categories allow researchers to look at the strategic performance (i.e. the use of different strategies) of the "whole learner" in a broad way rather than just get a glimpse of some aspects of the learner (e.g., the metacognitive or cognitive) that are involved in the learning process (Hsiao \& Oxford, 2002; Oxford, 1996). More importantly, Hsiao and Oxford (2002) found statistical support that Oxford's (1990) six-factor strategy inventory is a well-justified framework of strategy types and offers a systematic categorization of distinct strategy constructs. They also found evidence in support of Oxford's (1990) idea of a mutual support network among various kinds of L2 learning strategies-i.e. learners' use of certain strategies is intertwined with the use of other L2 learning strategies and the six categories reinforce one another.

Given the stability of SILL as an instrument that works reliably in both ESL and EFL contexts, we decided to use it in an EFL context in which, to our knowledge, it has not been used before-i.e. with Russian university students, studying English for professional purposes. One of the few studies on the strategic competence of Russian university students is a study by Levine, Reves and Leaver (1996), investigating the relationship between language 
learning strategies and cultural-educational factors. The participants of the study were immigrants from the old Soviet Union regime $(n=63)$ and "old-timers” ( $n=54)$ (living in Israel for over five years) enrolled in a university pre-academic program. The results of the study suggested that the immigrants from the old Soviet Union regime preferred to use traditional strategies such as rote learning, mechanical memorization of grammar rules and lists of words, translating verbatim into Russian, which were more rigid and less creative strategies, whereas the "old-timers" favored the use of communicative strategies and a more associative, flexible, and creative approach to information processing. The semi-structured interviews the researchers conducted unveiled stark differences between the educational experiences of the two groups: The immigrant students referred to the Russian educational system as "highly formal and impersonal", with little to no student-initiated discussions or creative assignments. These personal experiences confirmed the findings of earlier studies based on observations of Russian EFL teachers, and teachers of Russian as a second or foreign language.

The researchers concluded that students' strategy preferences can be largely influenced by the learning habits imposed by an educational system -in this case, the Russian system being “a strictly centralized, formal, and highly prescriptive system”, while the Israeli one was described as being "more autonomous, free, thought-provoking” (Levine et al., 1996: 43). The authors further explained that such disparate learning strategies usually cause a great deal of problems to both the students as well as the educational programs they join in other countries because of the mismatch between students' previous educational experiences and the new expectations of the host programs. In this regard, the current experiment we conducted with Russian university students had the potential to uncover the change in their strategy repertoire, compared to Levine et al.'s (1996) study that can partially be attributed to changes in the educational practices, at least, at the tertiary level of language education.

The present study addressed the following research questions:

1. How do the $1^{\text {st }}$ year students compare to the $4^{\text {th }}$ year students in terms of their strategy repertoire?

2. To what extent do students find the strategy inventory (SILL) applicable to their specific socio-cultural context of educational experience? Can they identify other strategies (not included in the inventory) that they have found to facilitate their learning?

3. Can SILL be used to evaluate the effects of language and TEFL training on university students' awareness of language learning strategy use? 


\section{METHOD}

\subsection{Participants}

The participants of the present study $(N=61)$ were recruited at a large university in Russia from the body of students enrolled in their first $(n=23)$ and fourth year of study $(n=38)$ in an English Linguistics Program. The University, with approximately 4,000 full-time students enrolled, is located in close proximity to Moscow. It has four main departments (i.e. System Analysis and Management, Natural Sciences and Engineering, Economics and Management, Humanities and Social Sciences), running 26 different programs (including English Linguistics). All participants were native speakers of Russian ( $n_{\text {Female }}=57, n_{\text {Male }}=4 ; M_{\text {Age }}=$ 19.5) in their first semester of study in the respective year of enrollment. At the time of the experiment, the $1^{\text {st }}$ year students reported to have studied English for approximately eight years ( $M=8.1$ years) and the $4^{\text {th }}$ year students-for over ten years ( $M=10.5$ years) which shows extensive English language learning experience both prior to being admitted to the Program as well as towards the end of their study there.

In addition, the students have to take tests in English, Russian and Russian literature as entrance exams to satisfy their admission requirements. In 2011, the acceptable passing score for admission to the English Linguistics Program was 210 (out of 300), which was the highest in comparison with the admission requirements for other programs in the same university. The English language exam is taken to confirm the high level of English proficiency the students have prior to entering the Linguistics Program. The duration of the coursework in the Program is four years and it involves intensive learning of English as a foreign language (over 2,800 contact hours) in addition to coursework focusing on TEFL pedagogy as well as translation and interpreting. The learning process is organized into series of lectures, practice classes as well as a lengthy practicum. About $50 \%$ of the learning time is devoted to practice classes in foreign languages (i.e. English, German, or French). Each semester students are required to hand in one paper/project on the subject matter relevant to the coursework they are taking and, at the end of each semester, students' language skills are evaluated by means of oral and written examinations. Thus, in terms of previous experience with language learning, the first year students represented the body of students who have just started their tertiary education with a strategy repertoire from whatever language learning experience they have had previously, while the fourth year students represented the body of students who have received some TEFL training and, potentially, have increased their language learning strategy repertoire over the course of their education.

In addition to satisfying the rigid admission requirements for English proficiency, the participants self-rated their proficiency on a scale ranging from "excellent" = 4 to "good" $=3$, "fair" $=2$, and "poor" $=1$. Not surprisingly, the $4^{\text {th }}$ year students rated their proficiency level $(M=3.1, S D=.31)$ as significantly higher, $t(59)=-6.6, p<.001$, than the $1^{\text {st }}$ year students $(M$ 
$=2.3, S D=.64)$, which shows a noticeable self-perceived improvement in proficiency as a result of the language training the students underwent in the course of their studies in the Program.

The majority of the participants (90\%) indicated that the purpose of their learning English is to get employment in translation and/or interpreting, teaching, or research. Only a small number of students (10\%) stated that they are learning English in order to communicate with native speakers, understand other cultures, study abroad, work, or travel abroad.

\subsection{Instrument and procedure}

The instrument consisted of two parts: The first part was designed to collect demographic information about the participants (age, gender, native language, self-rated proficiency) in addition to some information regarding their language learning experience in general as well as where they see themselves professionally after completing their studies in English Linguistics. The second part was a survey which consisted of statements related to the six categories of language learning strategies, identified by Oxford (1990). The survey-Oxford's (1990) SILL - was intended to capture students' frequency of using those strategies and whether the two groups show any differences within and across the categories. Each strategy statement was accompanied by a five-point Likert scale on which the participants had to indicate the frequency with which they used the strategy, by circling a number from 1 to 5 i.e. "never $=1$ " to "always $=5$ ".

The items from the original SILL were randomized. Two additional items, adopted from Lee and Oxford (2008), were also included in the survey — one, a binary (yes or no) question, accompanying each of the strategy statements, which required the participants to decide whether or not each language learning strategy could be used in Russia.

Example:

\begin{tabular}{|l|lllccc|}
\hline $\begin{array}{l}\text { 1. I say or write new English words } \\
\text { several times. }\end{array}$ & $\begin{array}{l}1 \\
\text { Can this strategy be used in Russia? Yes }\end{array}$ & No \\
\hline
\end{tabular}

The second one was a question which asked the participants to identify and write down any new strategies they have been using but were not listed in the survey. The data from this question were analyzed qualitatively.

The survey was administered in English as the participants in the study were at a high level of proficiency. The participants had no knowledge of and had never taken SILL before the experiment. The students completed the survey in class and the time provided did not exceed one class period (each class period is $120 \mathrm{~min}$. with a 10-minute break). 


\subsection{Scoring}

Each statement was assigned a number for scoring purposes (e.g., ranging from "never" = 1 to "always" = 5 ) and these data were analyzed quantitatively. For the Likert-scaled strategy-use items on the survey, the following ranges were used to interpret the means: 3.5 to 5.0, corresponded to high strategy use, 2.5 to 3.4-medium use, and 1.0 to 2.4-low use (Oxford, 1990). The positive and negative responses to the binary question regarding the applicability of learning strategies in Russia were assigned numeric values-i.e. "yes” = 1 and "no" = 0 . The qualitative data from the last item in the survey were summarized, categorized and analyzed in terms of patterns and frequency of mention of different strategies, additionally listed by the students.

\section{RESULTS}

To compare the strategy use of $1^{\text {st }}$ and $4^{\text {th }}$ year students an independent $t$-test was conducted. Table 1 displays the means and standard deviation for $1^{\text {st }}$ year and $4^{\text {th }}$ year students. Stem and leaf plot diagrams for all categories of strategies suggested that the variables were mostly normally distributed. The box plot diagrams for social strategies showed that there were two outliers from the group of first year students. After their effect was examined on the rest of the analysis, they were not excluded from the data since they did not influence statistically any of the comparisons.

\begin{tabular}{|c|c|c|c|c|}
\hline \multirow[t]{2}{*}{ Strategies } & \multicolumn{2}{|c|}{$\begin{array}{l}1^{\text {st }} \text { year students } \\
(n=23)\end{array}$} & \multicolumn{2}{|c|}{$\begin{array}{l}4^{\text {th }} \text { year students } \\
(n=38)\end{array}$} \\
\hline & $M$ & $S D$ & $M$ & $S D$ \\
\hline Metacognitive & 3.66 & .66 & 3.93 & .57 \\
\hline Cognitive & 3.53 & .49 & 3.76 & .46 \\
\hline Memory & 3.22 & .49 & 3.23 & .54 \\
\hline Compensatory & 3.48 & .60 & 3.58 & .54 \\
\hline Affective & 2.94 & .46 & 2.90 & .57 \\
\hline Social & 3.41 & .53 & 3.79 & .57 \\
\hline
\end{tabular}

Table 1. Means and Standard Deviations of the Learning Strategies Use among the $1^{\text {st }}$ and $4^{\text {th }}$ Year Students

On average, the $1^{\text {st }}$ year students did not differ from the $4^{\text {th }}$ year students in their use of metacognitive, memory, compensatory, affective, and cognitive strategies $(p>.05)$. The two groups only differed in their use of social strategies, $t(59)=-2.646, p<.05$, with the $4^{\text {th }}$ year students employing noticeably more social strategies than the $1^{\text {st }}$ year participants. These results indicated that beginning English Linguistics students already have most of their 
language learning strategies in place when they enter the Program and their further education deepens rather than dramatically changes their strategy preferences and frequency of use.

To find out the order of the preferred categories of strategies each group favored the most, pair-wise comparisons evaluated the magnitude of the differences between the strategy categories for each group. For the1st year students, the use of metacognitive strategies differed significantly from the use of memory, $t(22)=3.026, p<.05$, and affective strategies, $t(22)=5.543, p<.001$. The cognitive strategies differed significantly from the memory, $t(22)=3.417, \quad p<.05$, and affective strategies, $t(22)=5.863, p<.001$. Finally, the compensatory strategies differed noticeably from the memory, $t(22)=2.277, p<.05$, and the affective strategies, $t(22)=4.948, p<.001$; the social—from the affective, $t(22)=3,913, p$ $<.05$, and the memory - from the affective, $t(22)=2.546, p<.05$. All other comparisons were non-significant.

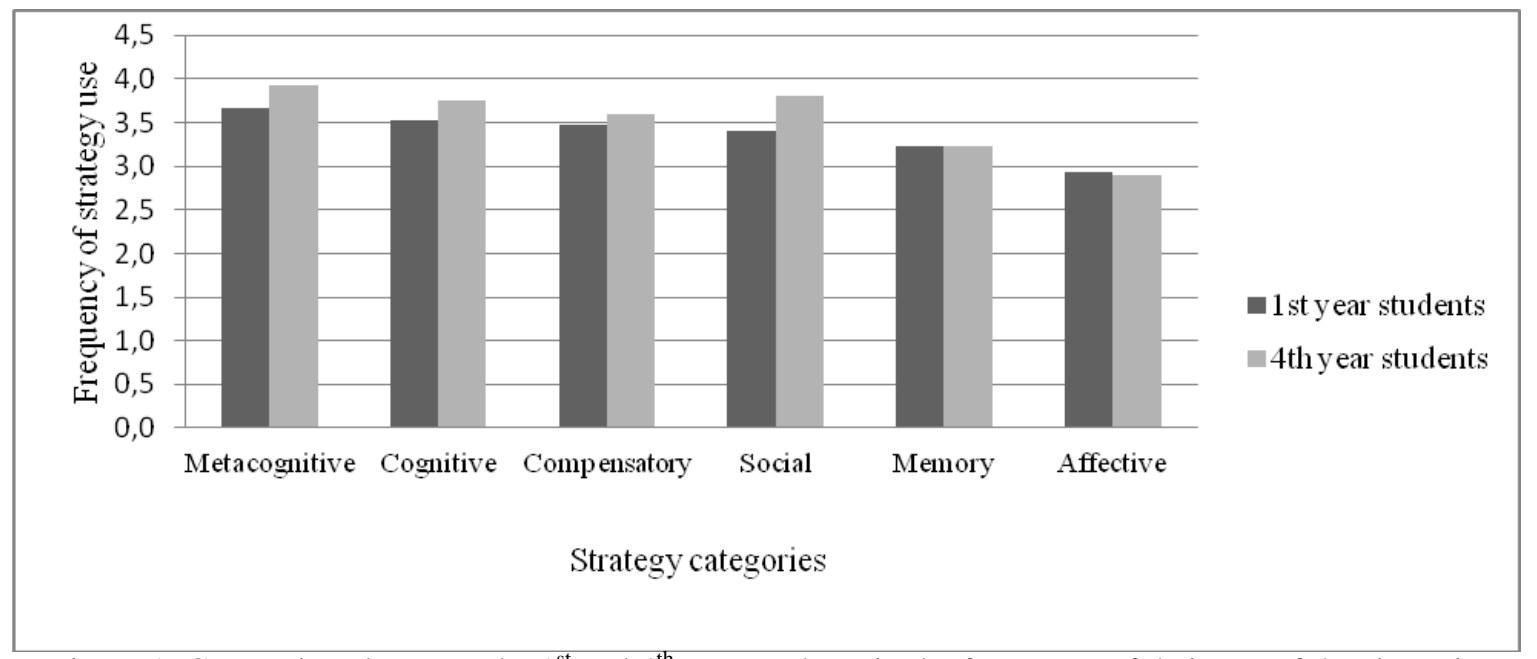

Figure 1: Comparison between the $1^{\text {st }}$ and $4^{\text {th }}$ year students in the frequency of their use of the six main categories of strategies

For the $4^{\text {th }}$ year students, the frequency of use for the metacognitive strategies differed significantly from their use of cognitive, $t(37)=2.087, p<.05$, compensatory, $t(37)=3.503$, $p<.001$, memory, $t(37)=7.044, p<.001$, and affective strategies, $t(37)=9.723, p<.001$. The social strategies differed significantly from the compensatory, $t(37)=2.273, p<.05$, memory, $t(37)=6.308, p<.001$, and affective strategies, $t(37)=8.366, p<.001$. Finally, the compensatory strategies differed noticeably from the memory, $t(37)=3.441, p<.05$, and the affective strategies, $t(37)=6.313, p<.001$, and the memory from the affective ones, $t(37)=$ $2,692, p<.05$. All other pair wise comparisons were non-significant.

The analysis of the question whether or not each of the strategies can be used in Russia showed that the affective and compensatory strategies were rated as the least possible to use in Russia, compared to the other strategies. All participants unanimously agreed on the applicability of only five specific strategies. On average, the two groups did not differ 
significantly in their rating of the main categories of strategies; they differed in their opinion on only five individual strategies which will be discussed in the following section.

Since the test instrument, adopted in the study, was originally designed with a different purpose in mind, compared to our purpose, it was important to assess its internal consistency reliability as a whole as well as in terms of the six categories of strategies. Overall, the reliability analysis for all items comprising the survey yielded a Cronbach's alpha of .87 which suggested that the instrument as a whole has high internal consistency reliability-i.e. all items consistently measured the participants' use of learning strategies. The reliability analysis of the separate categories, though, showed greater variability ranging from relatively high values for the metacognitive (Cronbach's alpha $=.76$ ) and cognitive strategies scale (Cronbach's alpha $=.72$ ) but weaker consistency values for the other categories-i.e. memory strategies (Cronbach's alpha $=.58$ ), social strategies (Cronbach's alpha $=.54$ ), compensatory strategies (Cronbach's alpha $=.37$ ), and affective strategies (Cronbach's alpha $=.14$ ). This suggested that the students did not respond as consistently to some strategy categories in the survey as they did to others which may have been a result of their different interpretation of the items themselves or the small number of items on some of the scales (e.g., the compensatory, effective, and social scales consisted of only six items, compared to the other categories).

Finally, the qualitative results of the open-ended question in the survey indicated that the response rate was much higher among the $4^{\text {th }}$ year students, where $95 \%$ of the participants responded, compared to the response rate of $22 \%$ among the $1^{\text {st }}$ year students. More interestingly, the $4^{\text {th }}$ year participants listed additional strategies that they use but were not included in the survey (see Table 2), while the responses of the beginning students were limited to the use of media (books, internet and movies) which, in fact, duplicated strategies already included in the survey. The suggested strategies will be discussed in greater detail in the next section.

\begin{tabular}{ll}
\hline Strategies & Frequency of mention \\
\hline Creating exercises/tasks & $14(37 \%)$ \\
Communicating in English with native speakers, self, friends, and family & $14(37 \%)$ \\
Writing fresh context stories/sentences & $11(29 \%)$ \\
Travel abroad & $8(21 \%)$ \\
Participating in oral activities_-e.g., shows, presentations, discussions & $6(16 \%)$ \\
Using a monolingual dictionary & $4(10 \%)$ \\
Giving definitions to words and memorizing them & $4(10 \%)$ \\
Peer teaching & $4(10 \%)$ \\
Playing games in English & $4(10 \%)$ \\
Learning/translating songs in English & $3(8 \%)$ \\
Writing poems in English & $3(8 \%)$ \\
Naming/translating into English objects on the street & $2(5 \%)$ \\
\hline
\end{tabular}

Table 2. New Strategies Identified by the $4^{\text {th }}$ Year Students Enrolled in the English Linguistics Program 


\section{DISCUSSION}

Language learning strategies have been of consistent pedagogical interest for a long time because they directly relate to strategies used by L2 learners for learning or using the target language (Cohen, 1998). They can also help learners improve their perception, reception, storage, retention, and retrieval of language information (Oxford, 2003) which is one of the goals of successful language learning. From a learning point of view, strategies that are effectively employed "make learning easier, faster, more enjoyable, more self-directed, more effective, and more transferable to new situations" (Oxford, 1990: 8). From a teaching point of view, strategies are aimed at developing a sense of autonomy among L2 learners so that learning can take place both in and out of the classroom. In this regard, all parties involved in the learning process have an invested interest in strategy development which, however, has been primarily studied from learners' point of view rather than from an institutional or program evaluation perspective. The present study was an attempt in this direction.

The first question we addressed in the study was to evaluate the effectiveness of students' TEFL training in strategy use consciousness-raising by comparing the strategy repertoire of $1^{\text {st }}$ year students to the $4^{\text {th }}$ (last) year students in an English Linguistics Program at a Russian university. The overall results suggest high and medium strategy use across both groups, with the only difference between the beginning and the last year students being in their use of social strategies. The relatively high use of learning strategies and insignificant difference between the two groups across the metacognitive, cognitive, compensatory, memory, and affective categories can be explained by students' majoring in English Linguistics. In general, it is a very demanding Program in terms of initial language proficiency level among the newly admitted $1^{\text {st }}$ year students as well as performance throughout the length of the program. Learning English for professional purposes in such programs requires mastery of an advanced level of English, fluency and clarity of speaking in public, in addition to cultural, pedagogic, and other professionally related competences. Thus, students are prompted to use multiple learning strategies, particularly metacognitive and cognitive, in order to progress and maintain their language achievements at a high level.

The compensatory strategies, which are strategies that allow learners to fill in gaps in their language knowledge by switching to their native language, making up words, using gestures, inferencing, etc., also did not show noticeable increase across the groups (see Table 1). While there is no doubt that these strategies are important for the development of some aspects of speaking and listening, Taguchi (2002) has pointed out that the use of compensatory strategies decreases with more proficient students. In fact, the $1^{\text {st }}$ and $4^{\text {th }}$ year students did report to make a fairly frequent use of the compensatory strategies $\left(M_{1 s t}\right.$ year Ss $=$ 3.48 and $M_{4 \text { th year Ss }}=3$. 58), so the lack of difference between the groups may possibly be explained by the nature of the Program itself-i.e. training students to use English 
professionally as TEFL instructors and interpreters, which strongly discourages "guessing" and compensating for the lack of language knowledge; instead, it encourages "knowing" the language. In addition, the nature of testing in this program may also be a reason for the nonesignificant difference between the $1^{\text {st }}$ and $4^{\text {th }}$ year students. Lee and Oxford (2008), for instance, connect the extensive use of compensatory strategies among high school students in Korea to the frequent use of multiple-choice entrance examinations. The authors further suggest that multiple-choice tests might promote the use of compensatory strategies as students try to guess the right choice from the context even though the details are not known or understood. By contrast, in Russia in general, university education involves more openended oral and written examinations, which do not favor compensatory strategies.

The noticeable difference in the use of social strategies between the $1^{\text {st }}$ and $4^{\text {th }}$ year students was an interesting finding as it revealed that, as the students progressed through their studies, not only their desire to communicate in English increased but they have also started to consciously recognize these strategies as a way of honing their communicative skills in English. In this regard, Hong-Nam and Leveall (2006) made an important point about the positive influence of intensive language studies on the use of social strategies. In the same fashion, the English Linguistics Program we surveyed in this study can be considered to be a highly intensive language program as the students are exposed to English on a daily basis with many oral and interactive activities implemented in the curriculum. Also, in response to the open ended question which asked the participants to list additional strategies that they use but have not been mentioned in SILL, the $4^{\text {th }}$ year students emphasized the importance of communication with peers, family members and native speakers, which indicated a positive trend in their proactive social strategy use.

The affective strategies were reported to be used most infrequently by both groups which may largely be a result of the cultural peculiarities and formal relationships between students and instructors at Russian universities. Communicating emotions and feelings in the educational setting is not common in Russia due to the greater power distance and authoritative atmosphere in the classroom. Thus, students are not encouraged to discuss their feelings with regard to their language learning or any other subject area. Learning English for professional purposes may also have something to do with the medium use ( $M_{1 \text { st year ss }}=2.94$ and $\mathrm{M}_{4 \text { th year ss }}=2.90$ ) of affective strategies among the participants in that students most probably understand the necessity of being successful in learning English regardless of their emotional discomforts.

The analysis of the preferred order of strategy categories aimed at finding out whether, over the four-year period of education, the students changed the priority of some of the strategies they use as a result of their growth linguistically and professionally. Interestingly, the comparisons showed that there is some change in the strategy prioritization among the $1^{\text {st }}$ and $4^{\text {th }}$ year students, which can largely be attributed to the effects of their training to perfect 
their language skills since strategies are conscious actions that L2 learners select to use because they realize that they work for them (Anderson, 2005). In this regard, knowing more about the patterns of shift between the beginning and last year students can be useful in promoting certain strategies early on in students' training as they will possibly help them accomplish their language learning goals better and faster. The analysis revealed that the $1^{\text {st }}$ year students put the highest on their priority scale the metacognitive, cognitive, compensatory, and social strategies (i.e. the differences between these categories were negligible), followed by memory strategies and, at the bottom of their priority scale, the affective strategies. The $4^{\text {th }}$ year students had a more finely grained priority scale-they put the metacognitive and social strategies at the top, followed by cognitive and compensatory strategies, below which were the memory strategies and, at the bottom-the affective strategies. The order of prioritizing among the $4^{\text {th }}$ year students revealed the greater importance they attached to the social strategies as equally important as the metacognitive ones, distinguishing these two categories from the contribution of the other strategies. It also shows that the last year TEFL-trained students exercised heightened conscious control on their own cognition through planning, arranging, and evaluating their own learning process while, at the same time, realizing the importance and the added value of being proactive in the social aspect of their mastery of English.

Our second question of research interest was about the extent to which students find the strategies included in SILL applicable to their specific socio-cultural context of educational experience (i.e. studying English as a foreign language in Russia) and whether there are other than the listed strategies that they have been using. Before the experiment, we did not have any assumptions about the usability of the SILL in Russian context since, to our knowledge, the instrument has never been tested in that context before. However, prior research in other countries (e.g., Olivares-Cuhat, 2002; Wharton, 2000) has pointed out that one learning strategy may be valued in one culture but deemed inappropriate in another. In this regard, we were interested in finding out what the students actually thought about the applicability of the strategies listed in SILL and whether there are strategies they use (which might be more specific to the local context of language learning) but not included in SILL (which is designed as a more universal strategy inventory).

Overall, both groups noted that it was possible to use all SILL strategies in Russia which underscores the applicability of this instrument to an EFL context where, to our knowledge, it has never been used. Overall, the two groups did not differ in any significant way in that each group agreed with the other on the applicability of most of the strategies to Russia between $81 \%$ and $96 \%$. This high agreement rate on the primarily communicative strategies included in SILL stands out in stark contrast to the findings of Levine, at al.'s (1996) study about Russian university students’ learning preferences, which we discussed earlier, implying the positive change in the EFL teaching area the Russian educational system 
has undergone. There were five strategies on which usability the two groups unanimously agreed, which also suggests that these are the strategies the students are continuously exposed to and, probably, constantly encouraged to use, i.e.:

- I watch English language TV shows spoken in English or watch movies spoken in English. (cognitive)

- I practice English with other students. (social)

- If I can’t think of an English word, I use a word or phrase that means the same thing. (compensatory)

- I remember a new English word by making a mental picture of a situation in which the word might be used. (memory)

- I use new English words in a sentence so I can remember them. (memory)

There was also a small number of strategies on which the two groups differed noticeably in their opinions, the first two being more supported by the $1^{\text {st }}$ year students while the rest of the strategies - by the $4^{\text {th }}$ year participants, i.e.:

- I find the meaning of an English word by dividing it into parts that I understand. (cognitive)

- I talk to someone else about how I feel when I am learning English. (affective)

- I use Internet resources in English (blogs, chat room, news, YouTube). (cognitive)

- I make up new words if I do not know the right ones in English. (compensatory)

- I notice if I am tense or nervous when I am studying or using English. (affective)

The question about the applicability of the strategies included in the strategy inventory to the specificities of the Russian socio-educational context was tightly linked to the open ended question which asked the participants to list additional strategies, not included in the SILL. Interestingly, primarily the $4^{\text {th }}$ year students responded to this item by listing new strategies which underscores again their heightened awareness and consciousness in being able to name additional strategies that help them as language learners and users. The higher involvement among the $4^{\text {th }}$ year students may also have been a result of their pedagogical TEFL training that has raised their professional sensitivity to strategy use and, at the same time, allowed them to discuss explicitly some less commonly used strategies that worked for them.

The qualitative analysis of the survey uncovered a good number of additional strategies that the $4^{\text {th }}$ year students put into use to experience the language they are learning in new contexts (see Table 2). In addition, these are strategies that are primarily communicationoriented which point to a positive shift of the English language instruction in Russia from being more formal, centralized, and prescriptive (Levine et al., 1996) to fostering communicative language usage among the TEFL-trained university students. 
As Wong and Nunan (2011) rightly point out, understanding good language learning requires attention to the social practices in the contexts in which individuals learn other languages as well as examination of the ways in which L2 learners exercise their agency in the process of learning in those particular contexts. In that sense, the key to understanding strategy use in different EFL contexts (which may come with much greater socio-cultural variability than ESL contexts) is the recognition that L2 strategy use is bound up not only to what students do individually but also to the opportunities their various communities offer them (Wong \& Nunan, 2011) as well as to what the local educational traditions consider to be valuable L2 learning practices. Evidently, the overall preferred style for the $4^{\text {th }}$ year students was communicative and the additional strategies they listed were all consistent with Norton and Toohey's (2004) assertion that effective language learners exercise human agency to gain access to opportunities and communities of language users that are external to the classroom.

The last question of interest was related to the possibility of using SILL (Oxford, 1990) as an existing instrument to evaluate the effectiveness of language and TEFL training on university students' self-awareness of strategy use. Since the test instrument was originally designed with a different purpose in mind compared to our purpose, it was important to evaluate its internal reliability as a whole as well as in terms of the six categories of strategies it comprises before coming with any conclusions and recommendations in this regard. Furthermore, our starting assumption was that this line of analysis has the potential to reveal the extent to which all categories (in this case, of strategies) "hang together" and measure the same characteristic (Huck, 2000) (in this case, students' use of learning strategies) in a context that, to our knowledge, has not been studied before in this respect (i.e. Russian university students enrolled in an English Linguistics Program).

The analysis for the whole instrument yielded a relatively high reliability value (Cronbach's alpha $=.87$-a correlation that indicates very good reliability in educational research [McMillan, 2012]) which confirmed that the instrument as a whole consistently measured the participants' use of learning strategies and can be used as a dependable instrument in this educational context. This result is in accord with similar findings of other studies using SILL as an instrument (e.g., Hsiao \& Oxford, 2002; see for an overview Oxford, 1996). The reliability analysis of the separate categories, though, showed greater variability in that the values for the metacognitive and cognitive strategies were relatively high; however, the consistency with which the students responded to the other categories progressively declined (see Results section above), especially for the compensatory (Cronbach's alpha = .37 ) and affective strategies (Cronbach’s alpha $=.14$ ).

One possible explanation lies in the socio-cultural specificities of the EFL situation as well as the high proficiency level of the L2 participants in general. As several researchers have pointed out (e.g., Chamot , 2005; Hsiao, 2004; Hsiao \& Oxford, 2002; Wong \& Nunan, 2011; Oxford, 2003), in addition to learners' internal processing preferences, learning 
strategies are sensitive to the learning context itself. In other words, on the one hand, L2 learners match the strategies they use to the nature of the language learning task they face, dependent on their understanding of their own learning processes and which strategies have been successful in the past (Hsiao, 2004). On the other hand, the interpretation of the L2 learning task is closely linked to the goals promoted within a learner's cultural context as one learning strategy may be valued in one culture but deemed inappropriate in another (OlivaresCuhat, 2002; Wharton, 2000). Thus, the interaction between these strong influences largely determines if a particular strategy can help a learner in a certain context achieve some learning goals that they deem important (Chamot, 2005), whereas other strategies may not be considered useful for that learning goal at a personal, institutional, and socio-cultural level. Along those lines, it is highly possible that the participants' less consistent response to the social, compensatory, and affective categories of strategies are a result of a mismatch between personal preferences and institutional and cultural values that do not favor the use of compensatory and affective strategies. When we add to this, the EFL context of learning, which does not offer readily as many opportunities for social communication to each and every EFL learner as an ESL learning context does, that may explain the decline in response homogeneity across these three strategy categories.

To wrap it up, in addition to being widely used for the purposes of evaluating learning strategy use, our findings allow us to argue that SILL as a whole can be used reliably as an evaluation tool of TEFL-track university programs for several reasons:

First, given that such programs are open to applicants from all over the country (and abroad), who have studied English in a wide variety of contexts prior to starting their college education, it should be important to any such program to evaluate their students' language learning strategy inventories from the start. This will allow program curriculum designers and instructors to find out what strategy knowledge their newly admitted students already have and what strategy knowledge needs to be emphasized in their course of study.

Second, such programs are specifically designed to train and educate would-be TEFL instructors, for whom "the content and the process for learning the content are the same" (Hammadou \& Bernhardt, 1987: 305). In other words, in TEFL-track programs, students are learning at the same time the subject area-content they are going to teach in the future as well as how to teach this content. So, it is of paramount importance to programs to make sure they not only teach the pedagogical implications of strategy development (as part of the teaching methodology coursework students take) but also offer their students' the experiential training of expanding their own strategy repertoires.

Third, given that the students in the English Linguistics Program, both the newly admitted as well as the graduating ones, are considered to be successful language users, such an analysis can potentially uncover what strategies are typically used by successful language learners in the specific cultural context of EFL learning. In that sense, SILL and its findings 
can be used as a pedagogical material in TEFL-training programs to make future TEFL teachers explicitly aware of their own strategy inventories and all other possible strategies that make a language learning experience successful in the local socio-cultural context of learning.

Finally, in many universities, programs are required to make self-evaluation reports over certain periods of time to show their "health," consistency, and progress over time. In this regard, in light of the findings of this study, we can strongly recommend the use of SILL and its findings as a possible measure of effectiveness of TEFL-track program's outcomes both as an evaluation tool of their students' strategy learning progress as well as their pedagogical growth. We also offered a practical methodology of carrying out such an evaluation, which we believe is applicable in a variety of cultural context. However, we should point out again here that the consistency of students' responses may not be equally high across all categories of strategies as some strategies may not be considered useful by the students for the accomplishment of certain learning goals at an institutional and/or sociocultural level. Nonetheless, our findings show that the instrument as a whole is highly reliable in Russian context as it has shown to be in several others.

\section{CONCLUSION}

Overall, the current study confirmed the usefulness of SILL not only as an objective measure of the strategy repertoire of EFL students at different levels of proficiency but also as an instrument that TEFL-training tertiary education programs can use to evaluate the impact and effectiveness of their curriculum and language instruction on their students' strategy development. The underlying assumption is that the more "stretched" strategy repertoires these pre-service TEFL students have (i.e. repertoires that are enriched with a wide range of strategies), the more prepared they will be to teach a wide variety of strategies once they enter the teaching profession. Prior research (Christison, 2003; Wong \& Nunan, 2011) has consistently found that teachers audit their own classroom practices to match them to the strategies they themselves favor (Wong \& Nunan, 2011). Along similar lines, given that the students in TEFL-track programs are both learners (i.e. in the course of their education, they are mastering the language they are going to use/teach professionally) and pre-service language teachers (i.e. they are simultaneously taking coursework that develops them pedagogically), this situation puts them in a unique position for developing complementary competencies that are tightly intertwined and inform each other. Thus, a TEFL-track program should make sure that its students experience as as many strategies (among other language skills) as possible as learners so that they would be able to "stretch" their own teaching styles and develop greater flexibility as teachers. 
In that sense, the present study was able to capture objectively some subtle differences between the strategy use of beginning and the last year students (both groups being considered advanced and successful language learners). The findings can be used to implement specific classroom activities, practices, and projects at the very start of their language training to create an enriched strategy-wise environment for the students as early as possible in their studies. By and large, considering that strategic competence is part and parcel of communicative competence and the students in this study showed high to medium use of almost all categories of strategies, the instructional style in Russia seems to show signs of a shift towards a communicative language teaching, especially at a university level. At the same time, the teaching style still remains to be formal in some areas such as grammar instruction, teacher-led dynamics in the classroom, program flexibility, teacher-student relationships, etc. These socio-cultural specificities of the local educational tradition, however, should not be seen as necessarily negative because, as this study has shown, they still allow TEFL students to develop "stretched" strategy repertoires, in which they can intertwine local (more formal, cognitive- and metacognitive-oriented strategies) with communication-oriented ones. On a final note, studies like this should aim to uncover not only what language learning strategies advanced and "successful" university students use but also what strategies TEFL-trained students will bring to the teaching profession as part of their university-based experience. We also hope we have been able to show that such studies can also be used as part of any formal or informal assessment of the effectiveness of TEFL-oriented programs to respond successfully to the global and local trends and demands in language teaching as they reveal fine details about the effects of students' training that otherwise may go unnoticed.

\section{REFERENCES}

Anderson, N. J. (2005). L2 learning strategies. In E. Hinkel (Ed.), Handbook of research in second language teaching and learning (pp. 757-771). Mahwah, NJ: Erlbaum.

Celce-Murcia, M. (Ed.). (2001). Teaching English as a second or foreign language. Boston, MA: Heinle \& Heinle.

Chamot, A. U. (2004). Issues in language learning strategy research and teaching. Electronic Journal of Foreign language Teaching, 1(1), 12-25.

Chamot, A. U. (2005). Language learning strategy instruction: Current issues and research. Annual Review of Applied Linguistics, 25, 112-130.

Christison, M. A. (2003). Learning styles and strategies. In D. Nunan (Ed.), Practical English Language Teaching (pp. 267-288). New York: McGraw-Hill.

Cohen, A. D. (1998). Strategies in learning and using a second language. London: Longman.

Cohen, A. D. (2003). The learner's side of foreign language learning: Where do style, strategies, and tasks meet? International Review of Applied Linguistics, 41, 279-291.

Hammadou, J. \& Bernhardt, E. (1987). On being and becoming a foreign language teacher. Theory into Practice, 26, 301-306.

Hong-Nam, K., Leavell, A. G. (2006). Language learning strategy use of ESL students in an intensive English learning context. System, 34, 399-415. 
Hsiao, T-Y. (2004). Testing a social psychological model of strategy use with students of English as a foreign language. Psychological Reports, 95, 1059-1071.

Hsiao, T-Y., \& Oxford, R. L. (2002). Comparing theories of language learning strategies: A confirmatory factor analysis. Modern Language Journal, 86, 368-383.

Huck, S. W. (2000). Reading statistics and research. Longman.

Lee, K. R., \& Oxford, R. (2008). Understanding EFL learners' strategy use and strategy awareness. The Asian EFL Journal, 10 (1), 7-32.

Levine, A., Reves, T., \& Leaver, B. L. (1996). Relationship between language learning strategies and Israeli vs. Russian cultural-educational factors. In R. Oxford (Ed.), Language learning strategies around the world: Cross-cultural perspective (pp. 35-45). Manoa, HI: University of Hawaii Press.

McMillan, J. H. (2012). Educational research: Fundamentals for the consumer. Boston, MA: Pearson.

Norton, B., Toohey, K. (2001). Changing perspectives on good language learners. TESOL Quarterly, 35 (2), 307-322.

Olivares-Cuhat, G. (2002). Learning strategies and achievement in the Spanish writing classroom: A case study. Foreign Language Annals, 35(5), 561-570.

Oxford, R. (1990). Language learning strategies: What every teacher should know. New York: Newbury House.

Oxford, R. L. (1996). Employing a questionnaire to assess the use of language learning strategies. Applied Language Learning, 7, 25-45.

Oxford, R. L. (2001). Language learning styles and strategies. In M. Celce-Murcia (Ed.), Teaching English as a second or foreign language (pp. 359-366). Boston, MA: Heinle \& Heinle.

Oxford, R. L. (2003). Language learning styles and strategies: Concepts and relationships. International Review of Applied Linguistics, 41 (2003), 271-278.

Oxford, R., Cho, Y., Leung, S., \& Kim, H-J. (2004). Effect of the presence and difficulty of task on strategy use: An exploratory study. International Review of Applied Linguistics, 42, 1-47.

Taguchi, T. (2002). Learner factors affecting the use of learning strategies in cross-cultural contexts. Prospect, 17 (2), 18-34

Wharton, G. (2000). Language learning strategy use of bilingual foreign language learners in Singapore. Language Learning, 50(2), 203-243.

Wong, L., \& Nunan, D. (2011). The learning styles and strategies of effective language learners. System, 39, 144-163. 